\title{
THE EFFECT OF CEMENT MODIFICATION ON THE RHEOLOGICAL PROPERTIES OF CEMENT PASTE
}

\author{
Eugenijus JANAVIČIUS ${ }^{\mathrm{a}}$, Mindaugas DAUKŠYS ${ }^{\mathrm{b}}$, Gintautas SKRIPKIŪNAS ${ }^{\mathrm{c}}$, \\ Džigita NAGROCKIENE்c, Ala DAUGÉLIENE் ${ }^{\mathrm{b}}$ \\ ${ }^{a}$ Department of Building Materials, Kaunas University of Technology, Studentu g. 48, 51367 Kaunas, Lithuania \\ ${ }^{b}$ Department of Civil Engineering Technologies, Kaunas University of Technology, \\ Studentu g. 48, 51367 Kaunas, Lithuania \\ ${ }^{c}$ Department of Building Materials, Vilnius Gediminas Technical University, \\ Sauletekio al. 11, 10223 Vilnius, Lithuania
}

Received 31 Aug. 2012; accepted 18 Jul. 2013

\begin{abstract}
Experimental tests have determined the effect of slag, opoka (silica-calcite sedimentary rock), silica fume $\left(\mathrm{SiO}_{2}\right)$ suspension, dolomite dust and sodium silicate solution (NaSS) together with the polycarboxylatether based plasticizing admixture on the yield stress and viscosity of Portland cement paste the rheological properties of which have been defined applying a rotational viscometer with co-axial cylinders. The tests have revealed that slag, opoka, silica fume suspension and dolomite dust added to cement paste by replacing $10 \%$ of Portland cement (by weight) have an effect on the yield stress and viscosity of the paste subject to the form and fineness of additive particles. When $10 \mathrm{wt} \%$ of Portland cement is replaced with slag cement, the yield stress of Portland cement paste reduces by about $25.9 \%$, and viscosity increases by about 3.5 times compared with the yield stress and viscosity of reference cement paste. The yield stress of Portland cement paste with $0.5 \% \mathrm{NaSS}$ admixture increases insignificantly, and viscosity grows approximately twice compared with reference cement paste. The tests have also showed that the modifying admixtures of Portland cement paste enable to control the rheological properties of cement paste.
\end{abstract}

Keywords: portland cement, plasticizing admixture, sodium silicate solution, cement slurry, yield stress, viscosity, viscometer.

Reference to this paper should be made as follows: Janavičius, E.; Daukšys, M.; Skripkiūnas, G.; Nagrockienė, D.; Daugèlienè, A. 2013. The effect of cement modification on the rheological properties of cement paste, Journal of Civil Engineering and Management 19(Supplement 1): S125-S130. http://dx.doi.org/10.3846/13923730.2013.851111

\section{Introduction}

The possibilities of using alternative secondary materials that modify the rheological properties of concrete mixes as well as the physical and mechanical properties and structure parameters of hardened cement systems are explored in order to contribute to global climate protection and reduce the use of pure Portland cement clinker, the production of which causes environmental impacts at all stages of the process (Nochaiya et al. 2010, Turk 2012, Grzeszczyk and Janowska-Renkas 2013, Hou et al. 2013).

Both yield stress and viscosity (apparent or plastic) are strongly dependent on the particle characteristics of the powders employed in preparing a blended cement/ fly ash paste with a constant volume fraction of water. By measuring the PSDs (cement particle size distribution (PSD)) of both mixture components, it was found that both particle densities and particle surface areas, as determined from these measured PSDs, are critical pa- rameters influencing rheological response. Yield stress is dominated by the particle density of the cement component, with the fly ash mainly acting as a diluent that effectively decreases the cement particle number density. A percolation-type relationship can be employed to relate yield stress to cement particle density in the blended systems. Viscosities are influenced by both cement and fly ash particles, with approximate linear relationships between plastic viscosity values and either total particle surface area or total particle density being found (Bentz et. al. 2012, Perrot et. al. 2012).

Cement slurry is concentrated suspensions of small and heavy particles so rheological measurements are suffering to the disruption of cement operation (Miranda et al. 2010). Using concentration of silica fume at different ratios the rheological properties gradually improve with increase concentration but one thing should be noted that rheological properties does not always truly represent the material property and sometime could be 
misleading because of high error involved in the fitting model i.e., Bingham model (Memon et al. 2013). Silica fume has a singular effect for improving cement slurry and set cement properties, such as decreasing free water and fluid loss, increasing compressive strength and significantly decreasing water permeability in high WCR (water to cement ratio) slurry (Shadizadeh et. al. 2010).

Fly ash is an effective cementitious filler for improving the performance of cement paste and concrete. Consequently, the addition of superfine fly ash could increase flowability at same strength, increase strength at same flowability, or increase both strength and flowability (Kwan and Chen 2013).

Authors (Mansour et al. 2010) in our work several rheological tests were carried out at $20{ }^{\circ} \mathrm{C}$, by using the stress controlled rheometer AR2000, on the fresh cement pastes incorporating $0 \%, 5 \%, 10 \%, 15 \%$ and $20 \%$ of metakaolin (MK). The MK exhibit better rheological parameters (viscosity, shear stress) and improve the cement paste flowability, especially the replacement rate of $10 \% \mathrm{MK}$ and $15 \% \mathrm{MK}$. Addition of MK improves the cement paste behaviour. It has significant effect when the replacement takes $10 \% \mathrm{MK}$ and $15 \% \mathrm{MK}$. Cassagnabere et al. (2013) examined the flow properties (slump, flow time, apparent viscosity at different shear rates) of cement/metakaolin-based mortars determined that metakaolins can produce significant differences in the flow of mortars, depending on their physical and chemical properties.

Sonebi et al. (2013) investigated the effect of different mineral admixtures and superplasticizer on the rheological properties of cement grout and determined that metakaolin increased yield stress, plastic viscosity, cohesion plate, and flow time due to the higher surface area associated with an increase in the water demand. Different types of extenders are used as the additives, such as bentonite, pozzolan; microspheres and foam are use in Light weight cement slurry. Silica fume particles in the filter cake decrease the loss of fluid in high permeable formation. This improves the permeability which increasing the performance of cement slurry (Shahriar and Nehdi 2012).

Sodium silicate solution $\left(\mathrm{Na}_{2} \mathrm{O} \cdot \mathrm{nSiO}_{2}\right)$, like a plasticizing admixture, contains nano-structures, whereas sodium silicate solution contains non-dissolved $\mathrm{SiO}_{2}$ particles with a radius of $0.7 \mathrm{~nm}$ size (Nordstrom et al. 2013). To obtain better characteristics of construction materials at a macro level, the formation of nano-phases must be controlled and the properties of such materials have to be analysed at a micro level because nano-admixtures act as supplementary crystallization centres in cementitious materials and change the direction and rate of physical and chemical processes (Raki et al. 2010, Sanchez and Sobolev 2010, Pacheco-Torgal and Jalali 2011). Hommer (2010), Najigivi et al. (2013) reported that new generation superplasticizers acted as dispersion agents thus actively affecting the cement hydration process and improving the nanostructure of cementitious materials.
The goal of research was to investigate the effect of the current content of cement modifiers and polycarboxylate ether based plasticizing admixture on the rheological properties of cement pastes using a rotational viscometer with co-axial cylinders.

\section{Methods and materials of research}

Two types of cement, namely Portland cement CEM I $42.5 \mathrm{~N}$ and blast furnace slag cement CEM III/B $32.5 \mathrm{~N}$, were used as binders in the tests. Both types are produced in AB Akmenés cementas (Lithuania). A comparison of these two cement types revealed that slag cement had a larger specific surface area than Portland cement and made $420 \mathrm{~m}^{2} / \mathrm{kg}$ and $360 \mathrm{~m}^{2} / \mathrm{kg}$, respectively. The content of blast-furnace slag in this cement is $70 \%$, and that of Portland cement is $30 \%$.

Composition I (control) of cement paste is designed only with Portland cement; Composition II is designed mixing appropriate amounts of Portland cement and blast furnace slag. The content of slag in Composition II cement is $49 \% .10 \%$ of cement content was replaced (by weight) with modifying admixtures: opoka (Composition III), silica fume suspension (Composition IV) and dolomite dust (Composition VI). Plasticizing admixtures and sodium silicate solution (hereinafter NaSS, Composition $\mathrm{V}$ ) were added to the cement mix in the liquid form together with water at $0.5 \mathrm{wt} \%$ (Table 1 ).

Table 1. Compositions of tested cement pastes

\begin{tabular}{cccccccc}
\hline & \multicolumn{3}{c}{$\begin{array}{c}\text { Amount of } \\
\text { cement, \% }\end{array}$} & \multicolumn{5}{c}{$\begin{array}{c}\text { Modifying additives and } \\
\text { admixtures, wt } \%\end{array}$} \\
\cline { 2 - 9 } & $\begin{array}{c}\text { CEM I } \\
42.5 \text { N }\end{array}$ & $\begin{array}{c}\text { CEM III } \\
32.5 \text { B }\end{array}$ & Opoka & $\mathrm{SiO}_{2}$ & Dust & Plast. & NaSS \\
\hline I & 100 & - & - & - & - & 0.5 & - \\
\hline II & 30 & 70 & - & - & - & 0.5 & - \\
\hline III & 90 & - & 10 & - & - & 0.5 & - \\
\hline IV & 90 & - & - & 10 & - & 0.5 & - \\
\hline V & 100 & - & - & - & - & 0.5 & 0.5 \\
\hline VI & 90 & - & - & - & 10 & 0.5 & - \\
\hline
\end{tabular}

The composition of cement paste was modified by replacing $10 \mathrm{wt} \%$ of cement with industrial by-products: dolomite dust was used for experimental research. For experimental research, silica fume suspension Centrilit Fume S (SF) and carbonate opoka from Stoniškès (replacing $10 \mathrm{wt} \%$ of cement) were used as active mineral additives.

One type of superplasticizers, namely a pure superplasticizer having the characteristics, including concentration $-36.1 \%$, $\mathrm{pH}$ index -4.4 and electrical conductivity $4.390 \mathrm{mS} / \mathrm{cm}$ based on polycarboxylatether ether (produced by MC-Bauchemie Miuler GmbH and $\mathrm{Co}$, Germany) was used in the conducted research. Another admixture used was sodium silicate water solution (produced by Lithuanian company Remesta) with dry $\mathrm{Na}_{2} \mathrm{O} \cdot \mathrm{nSiO}_{2}$ and water ratio 60:40 and an average density value of $1.382 \mathrm{Mg} / \mathrm{m}^{3}$. 
The dynamic viscosity of cement pastes was tested by means of Malvern Instruments vibro-viscometer SV-10 where two paddle type sensors are stimulated by an electromagnetic drive at a constant frequency in a $13 \mathrm{ml}$ container. The interval of viscosity measuring is $0.3-10000 \mathrm{mPa} \cdot \mathrm{s}$.

Cement pastes were mixed by an automatic forced mixer Automix in accordance with LST EN 196-1:2005. Cement and materials were dosed by weight, water and chemical admixtures were added by volume. Chemical admixtures were mixed into water used to produce slurry. The constant water/binder $(\mathrm{w} / \mathrm{b})$ ratio 0.27 was maintained during the entire test.

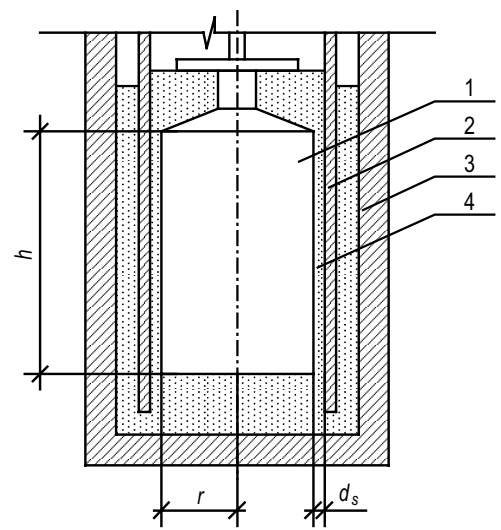

Fig. 1. Scheme for the rotational viscometer with coaxial cylinders: 1 - cylinder connected with a measuring scale $(r=$ $20 \mathrm{~mm}, h=60 \mathrm{~mm}) ; 2$ - internal (rotating) cylinder; 3 - external (fixed) cylinder; 4 - cement slurry

The rheological properties of slurry were tested using the rotational viscometer with coaxial cylinders $\mathrm{BCH}-3$. The simplified scheme for the viscometer is displayed in Figure 1.

Cement slurry was poured into a container (3) (external cylinder) rigidly fixed in the equipment stand. The internal cylinder (2) was able to rotate inside the external cylinder. The intrinsic friction of the layers of slurry (4) between the rotating internal cylinder and the cylinder (1) positioned in the internal cylinder and connected to a measuring scale made the internal cylinder (1) turn and the data displayed on the measuring scale changed. There was a $2 \mathrm{~mm}$ gap between the rotating internal cylinder (1) and the cylinder inside it.

The viscosity of slurry was tested at various speeds of the rotating cylinder, including 200,300, 400 and $600 \mathrm{rpm}$. According to the displayed scale, shear force $\mathrm{F}(\mathrm{mN})$ is calculated on the calibration curve that depends on the stiffness of the springs of the viscometer.

Shear rate $\bar{\gamma}$, for different rotating speeds of the cylinder (2), is calculated using the equation:

$$
\bar{\gamma}_{i}=\frac{2 \pi \cdot r \cdot n_{i}}{d_{s}}, \mathrm{~s}^{-1}
$$

where: $r$ is the radius of the cylinder connected to scale $m ; n_{i}$ is the rotation speed of the cylinder $(i=\overline{1,4})$, r.p.m.; $d_{s}$ is the distance between cylinders (1) and (2), m.
Shear stresses $\tau$ in cement slurry are calculated using the equation:

$$
\tau_{i}=\frac{F_{i}}{2 \pi \cdot r \cdot h}, \mathrm{~Pa},
$$

where: $F_{i}$ is shear force calculated from the calibration curve according to the turning angle of the scale, $\mathrm{mN} ; r$ and $h$ are the radius and height $(r)$ of the cylinder connected to the measuring scale.

The viscosity of cement slurry $\eta_{i}$ is calculated using the equation:

$$
\eta_{i}=\frac{\tau_{i}-\tau_{0}}{\overline{\gamma_{i}}}, \mathrm{~Pa} \cdot \mathrm{s},
$$

where $\tau_{0}$ is yield stress found out of the $\bar{\gamma}-\tau$ curve - the point where the curve crosses $\tau$ axis.

\section{Results of research}

The flow curves of Portland cement pastes of different compositions $(\mathrm{W} / \mathrm{C}=0.27)$ are presented in Figure 2. The curves in the figure show that the flow curve of Portland cement paste with cement CEM I $42.5 \mathrm{~N}$ and the plasticizing admixture added at $0.5 \mathrm{wt} \%$ (Composition I) is not linear, as in the Bingham plastic model, but has a shape of a curve. This is a property of dilatancy which is explained as a change in the distribution of solid phase particles and diminishing the liquid phase, i.e. the viscosity of a dispersive system increases with higher shear stress. The flow curve of Portland cement paste modified with slag cement CEM III 32.5 B (Composition II) corresponds with the flow curve of a quasi-plastic body, i.e. the viscosity of the dispersive system decreases with higher shear stress.

When $10 \mathrm{wt} \%$ of cement is replaced with opoka additive (Composition III, dotted curve), the flow curve of the cement paste comes close to the line compared with cement paste without the additive, and in the case of cement replacement with $10 \mathrm{wt} \%$ of silica fume suspension (Composition IV), the flow curve of cement paste corresponds to the linear Bingham model. From the angle of flow curve inclination towards the shear stress axis (Fig. 2), we may observe that both opoka and silica fume suspension additives reduce the dilatancy of cement paste.

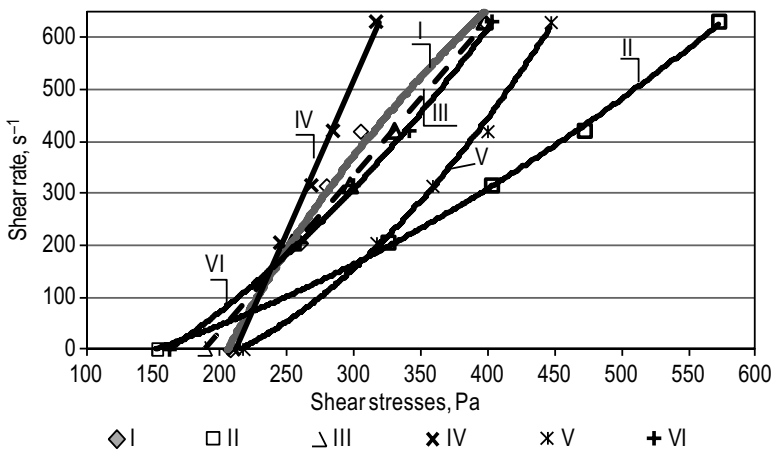

Fig. 2. The dependence of shear rates and shear stress in cement pastes of different composition 
The flow curve of cement paste with $0.5 \mathrm{wt} \%$ of polycarboxylatether based superplasticizer and $0.5 \mathrm{wt} \%$ of sodium silicate solution (NaSS) (Composition V) is declined away from the shear stress axis, compared with the flow curve of cement paste without NSS common to dilatant mixtures. The flow curve of cement paste with a dolomite dust admixture (Composition IV) is similar to the flow curves of cement pastes with opoka and silica fume suspension (Compositions III and IV). The flow curve is linear and corresponds to the Bingham plastic model, i.e. the viscosity of the dispersive system increases in proportion to higher shear stress.

Figure 3 presents a change in yield stresses depending on the composition of cement paste containing different cement modifiers (weight percentage).

Figure 3 shows that the replacement of $10 \%$ of Portland cement (by weight) with opoka and dolomite dust additives (Compositions III and VI) reduce the yield stresses of cement pastes by $9.1 \%$ and $21.7 \%$, respectively. The replacement of Portland cement with slag cement (containing 49\% of slag) (Composition II) reduces the yield stresses of the paste by $25.9 \%$. The modification of cement pastes with $0.5 \mathrm{wt} \%$ of the NaSS admixture and silica fume suspension (Compositions IV and V) have little effect on the yield stresses of the pastes compared with the yield stresses of control paste.

Figure 4 illustrates a change in the viscosity of Portland cement paste with different cement modifiers (weight percentage) at the shear rates of $205 \mathrm{~s}^{-1}$ and $630 \mathrm{~s}^{-1}$ subject to cement paste composition. Compared with control cement paste, the viscosity of cement pastes of all compositions increases, except for Composition IV where Portland cement was modified with silica fume suspension. The viscosity of cement paste, in which $10 \%$ of cement is replaced (by weight) with silica fume suspension, reduced twice compared with reference cement paste at the shear rates of $205 \mathrm{~s}^{-1}$ and $630 \mathrm{~s}^{-1}$.

Figure 4 demonstrates that the viscosity of cement paste with slag cement (Composition II) increased about 3.5 times compared with the viscosity of control Portland cement paste.

Daukšys et al. (2008) reported the results of a microscopy test showing that silica fume particles are smaller than 1 micrometer and have a spherical form; therefore they have a greater effect on the rheological properties of the paste. Silica fume suspension increases the yield stresses of cement paste and the viscosity of the paste reduces with a higher content of silica fume. When the suspension gets dry, very fine silica particles form the agglomerates of the size of cement particles; therefore, it is very important to find an appropriate manner of mixing in the silica fume in order to avoid the formation of agglomerates in cement paste. In our tests, silica fume was mixed in as suspension (Fig. 5).

Electronic microscopy tests on cement particles showed that the edges of most Portland cement particles were polished during grinding and that the majority of those had a cubic or even a spherical shape (Skripkiūnas et al. 2005) (Fig. 6a).

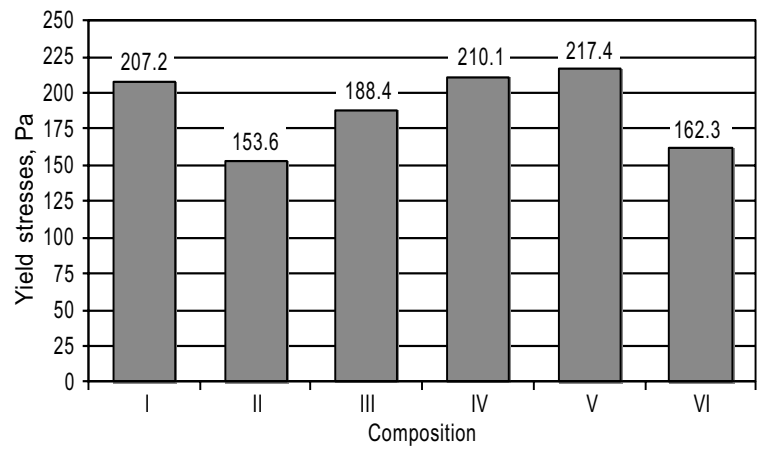

Fig. 3. Dependence of the yield stresses of cement pastes on different modifiers

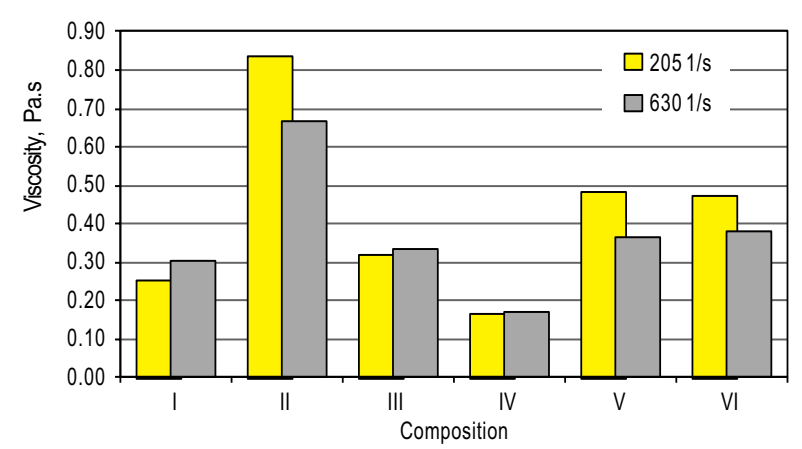

Fig. 4. Dependence of the viscosity of Portland cement pastes on different modifiers at the shear rates of $205 \mathrm{~s}^{-1}$ and $630 \mathrm{~s}^{-1}$

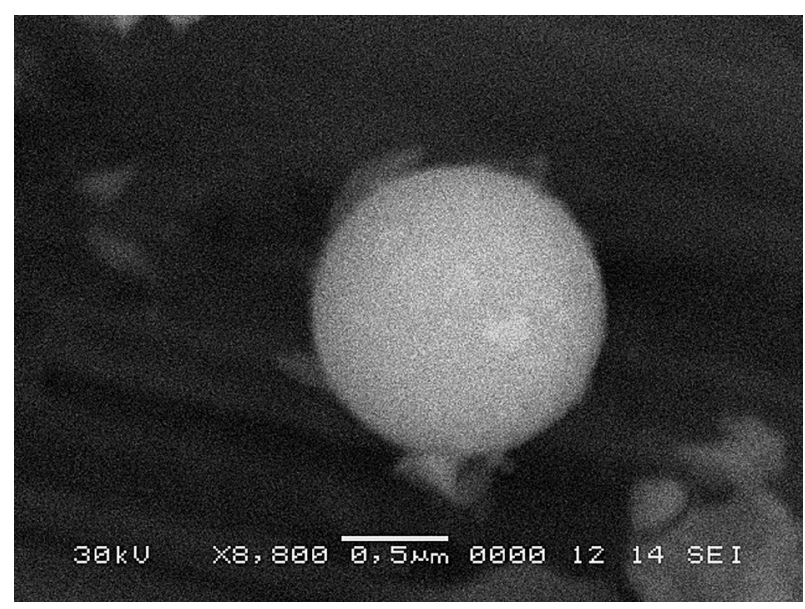

Fig. 5. A microscopy image of silica fume $\mathrm{SiO}_{2}$ particle

Granulated blast furnace slag particles are easy to recognize in slag cement: most of them are sharp and angular and covered with finer and rounder clinker particles (Fig. 6b). Slag cement particles are of a more irregular form than Portland cement particles. Skripkiūnas et al. (2005) described that yield stress and viscosity were higher in slag cement paste than in Portland cement paste due to an irregular and sharp shape of slag particles.

When $10 \%$ of Portland cement is replaced (by weight) with opoka additive (Composition III), an increase in the viscosity of cement paste compared with reference cement paste cement paste is insignificant. The 

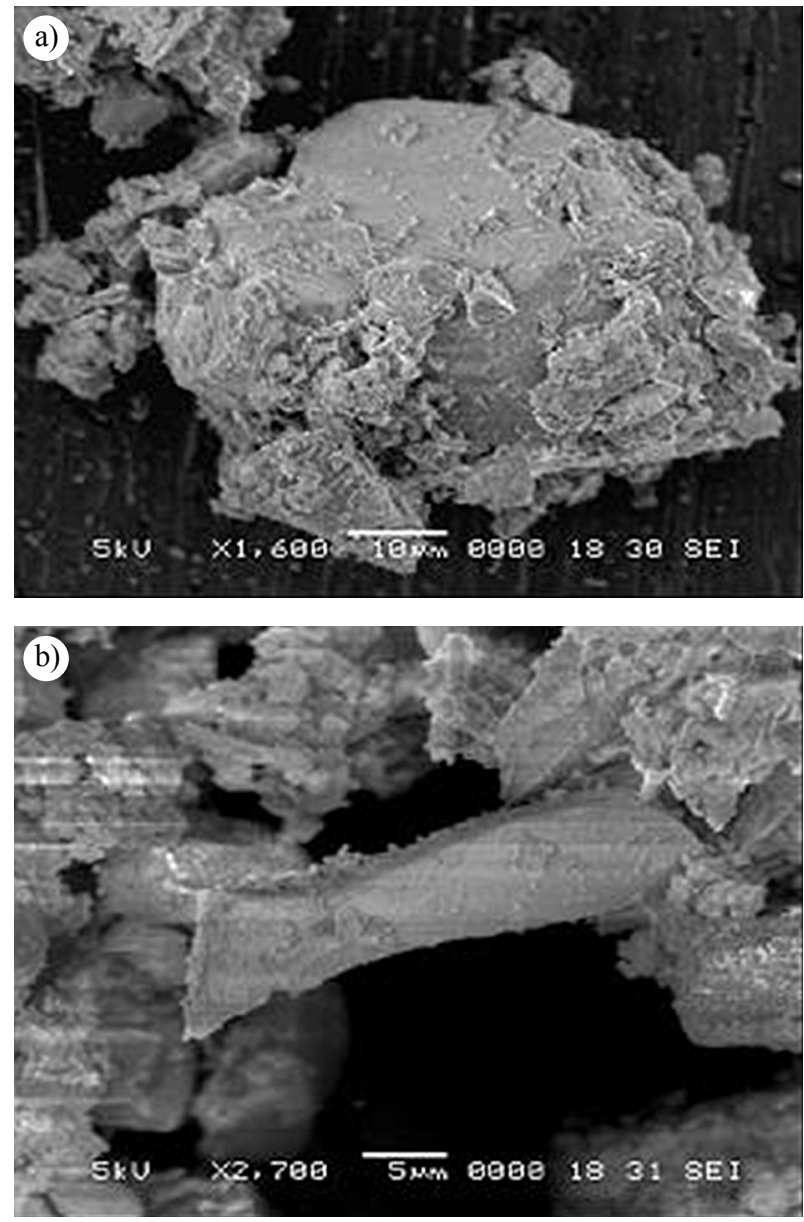

Fig. 6. Microscopy images of different cement particles: $\mathrm{a}$ - Portland cement particles; $\mathrm{b}$ - Slag cement particles

same trend is observed when Portland cement is replaced (by weight) with a dolomite dust additive (Composition IV). The results of viscosity tests on Portland cement paste modified with the polycarboxylatether superplasticizer added at $0.5 \mathrm{wt} \%$ and $\mathrm{NaSS}$ solution added at $0.5 \mathrm{wt} \%$ (Composition V) showed that NaSS solution increased cement paste viscosity 1.7 times at the shear rates of $205 \mathrm{~s}^{-1}$ and $630 \mathrm{~s}^{-1}$.

Daukšys et al. (2009) tested an integrated nanomodifying effect of polycarboxylate polymers and sodium silicate solution on the rheological properties of cement pastes (yield stress, viscosity and dilatancy) and agreed that sodium silicate solution could be used for modifying the rheological properties of the mixtures. The addition of NaSS at $0.5 \mathrm{wt} \%$ causes cement paste to thicken, which can be explained by various physical and chemical processes. One of the possible processes is the transformation of the dispersive system from sol to gel that is specific, semi liquid and semi solid continuous immobile thick mass formed through the dispersion of colloid particles in liquid. Sol is a colloidal dispersed system or colloidal solution with particle size in the dispersed phase ranging from 1 to $100 \mathrm{~nm}$. Sodium silicate solution contains non-dissolved $\mathrm{SiO}_{2}$ nano-particles that are $1-2 \mathrm{~nm}$ in size. New generation superplasticizers contain the particles of a nano-dispersion size. Therefore, these solutions can be regarded as colloidal solutions or sols. Such solutions tend to coagulate or turn into gels, i.e. the particles of colloidal solution stick together to form coarser aggregates that readily precipitate. Coagulation starts with diminishing the charge of colloidal particles and becomes very fast when charge becomes neutral. The coagulation of colloidal particles is promoted by adding electrolytes or opposite charge sol into colloidal solution by increasing the temperature of the solution or applying electrophoresis. Most of hydrophilic colloids coagulate in the presence of electrolytes, because hydrating electrolyte ions attach plenty of water, even the one connected with the particles of the dispersed phase.

The tests have showed that the modifying materials of Portland cement paste used in the research enable to control the rheological properties of cement paste.

\section{Conclusions}

1. The critical shear stress and viscosity of Portland cement paste is affected by the form and fineness of the particles of the active mineral admixture and interaction of sodium silicate solution with polycarboxylatether superplasticizer.

2. The replacement of Portland cement with slag cement (slag content up to $50 \%$ ) reduces the critical shear stress of cement paste by $25.9 \%$ and increases viscosity 3.5 times compared with reference cement paste.

3. The replacement of $10 \mathrm{wt} \%$ of Portland cement with opoka and dolomite admixtures reduces the critical shear stress of cement paste by $9.1 \%$ and $21.7 \%$, respectively, compared with reference cement paste.

4. The opoka additive insignificantly increases the viscosity of cement paste.

5. NaSS and silica fume suspension modifiers added at $0.5 \mathrm{wt} \%$ to the tested Portland cement pastes had an insignificant effect on the critical shear stresses of the pastes.

6. The replacement of $10 \mathrm{wt} \%$ Portland cement with silica fume suspension reduced the viscosity of the paste twice at the shear rates of $205 \mathrm{~s}^{-1}$ and $630 \mathrm{~s}^{-1}$ compared with reference cement paste.

\section{References}

Bentz, D. P.; Ferraris, Ch. F.; Galler, M. A. 2012. Influence of Particle Size Distributions on Yield Stress and Viscosity of Cement-Fly Ash Pastes, Cement and Concrete Research, 42 (2): 404-409.

http://dx.doi.org/10.1016/j.cemconres.2011.11.006

Cassagnabère. F.; Diederich, P.; Mouret, M.; Escadeillasb, G.; Lachemi, M. 2013. Impact of metakaolin characteristics on the rheological properties of mortar in the fresh state, Cement and Concrete Composites, 37(3): 95-107. http://dx.doi.org/10.1016/j.cemconcomp.2012.12.001

Daukšys, M.; Skripkiūnas, G.; Ivanauskas, E. 2008. Microsilica and plasticizing admixtures influence on cement slurry dilatancy, Materials science (Medžiagotyra) 14(2): $143-150$.

Daukšys, M.; Skripkiūnas, G.; Janavičius, E. 2009. Complex influence of plasticizing admixtures and sodium silicate 
solution on rheological properties of Portland cement paste, Materials Science - Medžiagotyra, 15(4): 349-355.

Grzeszczyk, S.; Janowska-Renkas, E. 2012. The influence of small particle on the fluidity of blast furnace slag cement paste containing superplasticizers, Construction and Building Materials, 26 (1): 411-415. http://dx.doi.org/10.1016/j.conbuildmat.2011.06.040

Hommer, H. 2010. Interaction of polycarboxylate ether with silica fume, Journal of the European Ceramic Society, 29 (10): $1847-1853$.

http://dx.doi.org/10.1016/j.jeurceramsoc.2008.12.017

Hou, P.; Kawashima, S.; Wang, K.; Corr, D. J.; Qian, J.; Surendra, S. P. 2013. Effects of colloidal nanosilica on rheological and mechanical properties of fly ash-cement mortar, Cement and Concrete Composites, 35 (1): 12-22. http://dx.doi.org/10.1016/j.cemconcomp.2012.08.027

Kwan, A .K. H.; Chen, J. J. 2013. Adding fly ash microsphere to improve packing density, flowability and strength of cement paste, Powder Technology, 234 (1): 19-25. http://dx.doi.org/10.1016/j.powtec.2012.09.016

Mansour, S. M.; Abadlia, M. T.; Bekkour, K.; Messaoudene. I. 2010. Improvement of Rheological behaviour of Cement Pastes by Incorporating Metakaolin, European Journal of Scientific Research, 42 (3): 442-452. http://dlibrary. umbb.dz:8080/jspui/bitstream/123456789/52/1/Improvement\%20of\%20Rheological\%20behaviour\%20of.pdf

Memon, K. R.; Shuker, M. T.; Tunio, S. Q.; Lashari, A. A.; G, Abbass. 2013. Investigating Rheological Properties of High Performance Cement System for Oil Wells, Research Journal of Applied Sciences, Engineering and Technology, 6(20): 3865-3870. http://maxwellsci.com/ print/rjaset/v6-3865-3870.pdf

Miranda, C. R.; Petrobras, R. D.; Fairbairn, T. 2010. New design of high-performance cement systems for zonal isolation: Influence on porosity, rheological parameters and chemical and mechanical resistance. in Proc. of the SPE Latin American and Caribbean Petroleum Engineering Conference, December 1-3, Lima, Peru.

Najigivi, A.; Khaloo, A.; Iraji, A.; Suraya, A. R. 2013. Investigating the effects of using different types of $\mathrm{SiO}_{2}$ nanoparticles on the mechanical properties of binary blended concrete, Composites Part B: Engineering, 54 (11): 52-58. http://dx.doi.org/10.1016/j.compositesb.2013.04.035

Nochaiya, T.; Wongkeo, W.; Chaipanich, A. 2010. Utilization of fly ash with silica fume and properties of Portland cement-fly ash-silica fume concrete, Fuel, 89(3): 768-774. http://dx.doi.org/10.1016/j.fuel.2009.10.003
Nordstrom, J.; Sundblom, A.; Vestergaard Jensen, G.; Pedersen, J. S.; Palmqvist, A.; Matic, A. 2013. Silica/alkali ratio dependence of the microscopic structure of sodium silicate solutions, Journal of Colloid and Interface Science, 397 (1): 9-17. http://dx.doi.org/10.1016/j.jcis.2013.01.048

Pacheco-Torgal, F.; Jalali, S. 2011. Nanotechnology: Advantages and drawbacks in the field of construction and building materials, Construction and Building Materials, 25 (2): 582-590.

http://dx.doi.org/10.1016/j.conbuildmat.2010.07.009

Perrot, A.; Lecompte, T.; Khelifi, H.; Brumaud, C.; Hot, J.;Roussel, N. 2012. Yield stress and bleeding of fresh cement pastes, Cement and Concrete Research, 42 (7): 937-944. http://dx.doi.org/10.1016/j.cemconres.2012.03.015

Raki, L.; Beaudoin, J.; Alizadeh, R.; Makar, J.; Sato, T. 2010. Cement and concrete nanoscience and nanotechnology, Materials 3(2): 918-942. http://dx.doi.org/10.3390/ma3020918

Sanchez, F.; Sobolev, K. 2010. Nanotechnology in concrete - A review Review Article, Construction and Building Materials, 24 (11): 2060-2071. http://dx.doi.org/10.1016/j.conbuildmat.2010.03.014

Shadizadeh, S. R.; Kholghi1, M.; Salehi Kassaei, M. H. 2010. Experimental Investigation of Silica Fume as a Cement Extender for Liner Cementing in Iranian Oil/Gas Wells. Iranian Journal of Chemical Engineering, 7 (1): 42-66. http://ijche.com/issues/2010-7-1/50.pdf

Shahriar, A.; Nehdi, M. L. 2012. Optimization of rheological properties of oil well cement slurriesusing experimental design, Mater. Struct., 45(9): 1403-1423. http://link. springer.com/article/10.1617/s11527-012-9841-2\#page-1

Skripkiūnas, G.; Daukšys, M.; Štuopys, A.; Levinskas, R. 2005. The influence of cement particles shape and concentration on the rheological properties of cement slurry, Materials Science - Medžiagotyra, 11(2): 150-158.

Sonebi, M.; Lachemi, M.; Hossain, K. M. A. 2013. Optimisation of rheological parameters and mechanical properties of superplasticised cement grouts containing metakaolin and viscosity modifying admixture, Construction and Building Materials, 38 (1): 126-138.

http://dx.doi.org/10.1016/j.conbuildmat.2012.07.102

Turk, K. 2012. Viscosity and hardened properties of self-compacting mortars with binary and ternary cementitious blends of fly ash and silica fume, Construction and Building Materials, 37 (12): 326-334.

http://dx.doi.org/10.1016/j.conbuildmat.2012.07.081

Eugenijus JANAVIČIUS. Doctor of technological sciences, lecturer at the Department of Building Materials, Kaunas University of Technology (KTU). Research interests: frost resistance and durability of concrete exposed to de-icing salts.

Mindaugas DAUKŠYS. Doctor of technological sciences, Assoc. Prof., the Head of the Department of Civil Engineering Technologies at Kaunas University of Technology (KTU). Research interests: new concrete placing technologies, concrete aggregates and admixtures, quality parameters of the concrete surface.

Gintautas SKRIPKIŪNAS. Doctor of technological sciences, Assoc. Prof., the Head of the Department of Building Materials at Vilnius Gediminas Technical University (VGTU). Research interests: building materials, concrete technology (rheological properties of Portland cement pastes, concrete structure and properties, concrete durability, modification of concrete properties).

Džigita NAGROCKIENE். Doctor of technological sciences, Assoc. Prof. at the Department of Building Materials, Vilnius Gediminas Technical University (VGTU). Research interests: durability and frost resistance, quality properties, structural and deformation characteristics of building materials.

Ala DAUGÉLIENĖ. Doctor of technological sciences, lecturer at the Department of Civil Engineering Technologies, Kaunas University of Technology (KTU). Research interests: construction technologies, construction operations, mathematical modelling of processes in construction. 